\title{
Molecular Genetic Aspects of Self-incompatibility in Brassicaceae
}

\author{
Hee-Jeong Jung ${ }^{1 \dagger}$, Nasar Uddin Ahmed ${ }^{1 \dagger}$, Jong-In Park ${ }^{1}$, Mi-Young Chung ${ }^{2}$, Yong-Gu Cho ${ }^{3}$, Ill-Sup Nou ${ }^{1 *}$ \\ ${ }^{1}$ Department of Horticulture, Sunchon National University, 255 Jungang-ro, Suncheon, Jeonnam 540-950, Republic of Korea \\ ${ }^{2}$ Department of Agricultural Education, Sunchon National University, 255 Jungang-ro, Suncheon, Jeonnam 540-950, Republic of \\ Korea \\ ${ }^{3}$ Department of Crop Science, Chungbuk National University, 52 Naesudongro, Heungdokgu, Cheongju 361-763, Republic of Korea
}

\begin{abstract}
Molecular genetic studies of self-incompatibility (SI) are the most accentuating part in the way of advancement of reproductive mechanisms in flowering plants. In the Brassicaceae plants, self-incompatibility has been mapped genetically to a single chromosomal location where several closely linked genes have been identified. Recently, various studies have provided a novel insight into the basis of specificity in the $S$-receptor kinase $(S R K)$ and $S$-locus protein 11 or $S$-locus Cysteine-rich $(S P 11 / S C R)$ interaction, the nature of the signaling cascade that culminates in the inhibition of 'self' pollen, and the physiological and morphological changes that are associated with transitions between the outbreeding and inbreeding modes of mating in the Brassicaceae. In this review, we discuss the current view of the molecular genetic aspects of the self-incompatibility in Brassicaceae.
\end{abstract}

Keywords Brassicaceae, Genetics, Recognition mechanism, Self-incompatibility

\section{INTRODUCTION}

Self-pollination occurs easily in hermaphrodite flowers, and leads to inbreeding depression and decreased genetic variation; therefore plants have evolved several mechanisms to avoid self-pollination. Self-incompatibility (SI) is defined as the inability of a fertile hermaphrodite seed plant to produce zygotes after self-pollination, which is surely the most elegant pollination system (de Nettancourt 2001). SI is a physiological barrier making it difficult or impossible for a flower to fertilize itself even though it may be abundantly pollinated with its own pollen and it is the commonest way in which plants avoid self-fertilization. SI involves the ability of a plant to discriminate between its own pollen grains and those of another plant and only allow pollen from a different plant to grow and fertilize the ovules. In relation to biological events, incompatibility and sterility are clearly different. Sterility is caused by non-functional male and/or female components, whereas in incompatibility there is a lack of seed formation in a specific male and female combination, both of which are functional. Because the final phenotypes in incompatibility and sterility are quite similar, this phenomenon was originally termed self-sterility. Taking the initial letter of sterility, the genetic locus regulating SI was termed the $S$-locus, which is still used as the authorized locus name. It is classified into heteromorphic and homomorphic type with respect to flower morphology. The homomorphic self-incompatibility of some species is controlled by a single locus, and those of the other species are controlled by multiple loci. In all the homomorphic systems, self-incompatibility is controlled by a multiallelic locus called $S$-locus and pollen is rejected by pistils having the same alleles. Homomorphic selfincompatibility systems can be divided into two major classes: gametophytic and sporophytic, which are distinguished by the expression of $S$-locus genes (de Nettancourt 1977). In the sporophytic form of self-incompatibility, the stigma surface is the site of recognition and the proteins in the outer coat of the pollen grain are recognized. This pollen surface material is derived from the parent plant, the

\footnotetext{
Received September 12, 2013; Revised September 17, 2013; Accepted September 23, 2013; Published September 30, 2013

*Corresponding author Ill-Sup Nou, nis@sunchon.ac.kr, Tel: +82-61-750-3249, Fax: +82-61-750-3208

${ }^{\dagger}$ These two authors equally contributed to this work.
} 
sporophyte or spore-bearing plant, not from the pollen grain itself, hence the name of this system. Plants in the Brassicaceae, Convolvulaceae, and other families are known to have sporophytic self-incompatibility. For instances, pollen grains from the $S^{1} S^{2}$ anther are rejected on the $S^{1} S^{2}$ pistil due to matching alleles, however, the pollen grains from the $S^{1} S^{2}$ anther are fully compatible on an $S^{3} S^{4}$ pistil, and fertilization occurs.

In SI plants of this family, pollen will not develop on a stigma that expresses the same alleles as the pollen parent. The various naturally occurring, classically defined $S$-alleles that have been described in Brassica have been arranged in a dominance series based on their genetic behavior relative to other alleles in heterozygous plants (Thomson and Taylor 1966). Molecular analysis of the $S$-locus region shows that this locus is a complex locus spanning many kilobases and containing several physically linked transcriptional units that cosegregate perfectly with SI phenotype (Boyes et al. 1997; Casselman et al. 2000). A subset of genes within the $S$-locus complex ( $S$-haplotype) is highly polymorphic as expected for genes involved in recognition, and specific combinations of allelic forms of each of these genes are thought to define different SI specificities. Thus, the $S$-locus may be viewed as a master recognition locus that encodes the function(s) required for the stigma to distinguish self-related from self-unrelated pollen. In other words, we are interested in Brassica SI from the viewpoint of both fundamental biology and agricultural applications. Thus, an understanding of the molecular mechanisms of SI in Brassica species is an important research target.

In this review article, we will summarize SI research in Brassicaceae plants, including molecular cloning of the male and female $S$ determinants, epigenetic regulation of dominance relationships between $S$-alleles, and evolution of the SI system.

\section{Genetics of Self-Incompatibility in Brassicaceae plants}

Bateman (1955) deciphered the genetics of SI in the family Brassicaceae in the early 1950s. He described the control of SI by a single Mendelian locus, the $S$ (Sterility) locus, which exists as multiple alleles or variants, each of which encodes a distinct mating specificity. As expected for a system in which new alleles have a reproductive advantage and therefore will increase in frequency toward equilibrium, the number of $S$-locus alleles is usually large, being estimated at 22 in Iberis (Bateman 1955), 34 in Raphanus (Sampson 1957), 30 in B. rapa (Nou et al. 1993), and more than 50 in Brassica oleracea (Brace et al. 1994). The various naturally occurring, classically defined $S$-alleles that have been described in Brassica have been arranged in a dominance series based on their genetic behavior relative to other alleles in heterozygous plants (Thomson and Taylor 1966). A classical genetic analysis has grouped the Brassica $S$ alleles into two categories based on their phenotypic effect on self-incompatibility characteristics. The first group of alleles (high-activity) is placed relatively high on the dominance scale and exhibits a strong selfincompatible phenotype in which an average of 0 to 10 pollen tubes develop per self-pollinated stigma. The second group of alleles (low-activity) demonstrates a weak or leaky self-incompatible phenotypic effect in which 10 to 30 pollen tubes develop per self-pollinated stigma and they are considered to be recessive (Nasrallah et al. 1991).

The $S$-locus holds a large number of alleles within a population by frequency-dependent selection (Wright 1939; Fisher 1958). This system involves self- or non-selfpollen recognition in the reproductive process. Several self recognition mechanisms have been discovered in multiple plant lineages. They are classified into two types of pollenside recognition, i.e., gametophytic (haploidy recognition) and sporophytic (diploidy recognition) self-incompatibility (Takayama and Isogai 2005). Self-recognition reaction requires two genes-one for the female (pistil) side and the other for the male (pollen) side- and allele-specific interaction between female and male molecules prevents self-fertilization to avoid inbreeding depression. Recombination between the two genes should be suppressed because recombination may disrupt the allele-specific self-recognition ability. Balancing selection on the $S$-locus increases the nucleotide diversity in regions around the two self-incompatibilityrelated genes. Sequence surveys of the $S$-locus region have been performed in Brassica species and Prunus mume, which employ sporophytic and gametophytic self-incompatibility systems, respectively (e.g., Boyes et al. 1997; Casselman et al. 2000; Entani et al. 2003; Fukai et al. 2003; Shiba et al. 2003). These studies have revealed extremely high nucleotide 
diversity in $10 \mathrm{~kb}$ in Brassica rapa (Shiba et al. 2003) and in P. mume (Entani et al. 2003). It has been thought that high nucleotide variation may result from the suppression of recombination in the entire $S$-locus region.

\section{SI recognition genes identified from stigma}

Until now, several closely linked genes have been identified at the $S$-locus. Two of them, $S L G$ (for $S$-locus glycoprotein; Nasrallah et al. 1985) and SRK (for S-locus receptor kinase; Stein et al. 1991), are thought to be involved in the perception of self-pollen by the stigma. Both genes are highly polymorphic, and both are expressed specifically at the surface of mature stigmas. Mutations in SRK (Goring et al. 1993; Nasrallah et al. 1994) and loss of SLG expression (Toriyama et al. 1991; Nasrallah et al. 1992; Shiba et al. 1995) have been associated with SI. SLG gene is about $1.3 \mathrm{~kb}$ in length and encodes a $55 \mathrm{kDa}$ glycoprotein secreted into the papillar cell wall. Although the deduced amino acid sequence of $S L G$ s are highly polymorphic, 12 conserved cysteine residues are found in common, suggesting the importance of the structure formed by the cysteine residues for the common function of the glycoprotein. There are several potential N-linked glycosylation sites, but only two conserved sites (Kusaba et al. 1997). The role played by SLG in the SI response started to be questioned after the characterization of selfincompatible plants which express a very low level of $S L G$, and, in particular, after the discovery of naturally selfcompatible haplotypes which express a high level of $S L G$ (Gaude et al. 1995). New observations suggest that $S R K$, rather than $S L G$, plays a key role in the SI reaction. The $S R K$ gene encodes a membrane-associated protein. A number of pieces of evidence indicate that a functional $S R K$ is required for SI response in Brassica. The predicted SRK protein consists of a potentially glycosylated extracellular domain ( $S$-domain) that shares extensive sequence similarity with SLG (90\%) within haplotypes and contains 12 cysteine residues found in all members of the $S$ gene family in the Brassicaceae. This domain is joined via a single-pass transmembrane domain to a cytoplasmic region that has sequence similarity to protein kinases. Bacterially expressed SRK kinase domains show serine/threonine autophosphorylation activity (Goring and Rothstein 1992).
SRK may be related to plant proteins involved in defense against pathogens, another plant recognition system (Pastuglia et al. 1997a). Other approaches to studying the SI signaling cascade have used Arabidopsis species, because the whole genome sequence of it has been determined and other genetic tools (e.g. T-DNA tag lines, many ecotypes and microarray expression data) are available. To produce self-incompatible $A$. thaliana by transformation, two approaches have been used. Nasrallah and co-workers introduced SP11 and SRK from self-incompatible $A$. lyrata into self-compatible $A$. thaliana (C24 ecotype) and the resulting transgenic $A$. thaliana, with both $S P 11$ and $S R K$, exhibited the SI trait (Nasarallah et al. 2002, 2004). Searches for SRK regulators led to the identification of several interacting proteins (Bower et al. 1996; Gu et al. 1998; Vanoosthuyse et al. 2003; Kakita et al. 2007b). Three of these, ARC1, THL1, and MLPK, have been shown to be involved in the SI response (Stone et al. 1999; Haffani et al. 2004; Murase et al. 2004). THL1 has been demonstrated to negatively modulate the kinase activity of SRK3 (Cabrillac et al. 2001).

\section{SI recognition genes identified from anther}

In Brassica species, pollen coat proteins (PCPs), which are derived from anther tapetum, are essential for pollen development. Analysis of PCPs, successfully lead to identification of the male $S$ determinant (Heslop-Harrison 1975). Initially, SLG-interactive PCPs were searched (Doughty et al. 1993), and these interactive molecules were then characterized as cysteine-rich small proteins (Hiscock et al. 1995; Stanchev et al. 1996; Toriyama et al. 1998; Doughty et al. 1998; Takayama et al. 2000a). The cysteinerich small proteins were shown to be $\mathrm{a}<10 \mathrm{kDa}$ basic pollen coat proteins (PCP) by an elegant in vitro bioassay in which PCPs were isolated and fractionated (Stephenson et al. 1997). Interestingly, a gene encoding PCP-like protein, SP11, was found to be located at the $S$-locus, near SRK in B. rapa; thus SP11 was the most likely candidate for the male $S$ determinant (Suzuki et al. 1999). Subsequently, it was demonstrated that $S P 11$ is the male $S$ determinant by using bioassay and transgenic experiments in B. rapa (Takayama et al. 2000b; Shiba et al. 2001). Furthermore, recently we showed the self-compatible phenotype in a 
transgenic line of B. rapa after silencing of SPI lgene (Jung et al. 2012). Around the same time, a gene termed $S C R$ ( $S$-locus cysteinerich protein) in B. oleracea was also cloned, and identified as the male $S$ determinant (Schopher et al. 1999). SCRs represent a new class of small, secreted, cysteine-rich proteins, distinguishable from members of the PCP family. The SCR gene is tightly linked to the $S L G / S R K$ pair and shows an anther specific developmentally regulated expression profile. Comparisons of the deduced amino acid sequence of SCR proteins from $21 S$ haplotypes revealed a high degree of polymorphism (Watanabe et al. 2000). Different studies also showed that $S P 11$ and $S C R$ are identical (Suzuki et al. 1999; Takayama et al. 2000b; Schopher et al. 1999). On the other hand, for studying the function of SPI1 in SI signaling cascade, Arabidopsis species and $B$. rapa were used because their whole genome sequence have been determined and other genetic tools (e.g. T-DNA tag lines, many ecotypes and microarray expression data) are available. Tsuchimatsu, Suwabe and co-workers introduced SP11 into the Wei-1 ecotype of $A$. thaliana, which has a functional SRK but shows SC, to produce a self-incompatible $A$. thaliana (Tsuchimatsu et al. 2010). Furthermore, we developed self-compatible $B$. rapa after silencing $S P 11$ gene in a self-incompatible $B$. rapa line (Fig. 1; Jung et al. 2012). After identification of $S L G$, $S R K$ and SP11 genes, many allelic genes were isolated (Watanabe and Hinata 1999; Watanabe et al. 2008), which made it possible for us to calculate the allelic diversity.

\section{S-linked genes involved in SI recognition}

To date, several $S$-linked genes have been identified in the region downstream of the $S L G$ genes $(\sim 15 \mathrm{~kb})$. Boyes and Nasrallah (1995) have described a gene, designated SLA (S-locus anther), of B. oleracea with anther-specific expression but Pastuglia et al. (1997b) showed that a functional $S L A$ gene is not required for the SI response in Brassica. Two S-linked genes SLL1 and SLL2 (for $S$ locus-linked genes 1 and 2, respectively) of B. napus are located downstream of $S L G$ gene (Yu et al. 1996). Although SLL1 and SLL2 are linked to the $S$-locus region, it is not clear whether these genes function in selfincompatibility or serve some other cellular roles in pollenpistil functions. The $S$-linked ClpP (protease homologue) gene also seems unlikely to function in the SI reaction because of its expression pattern (Letham and Nasrallah 1998). Alongside, the genes that exhibit sequence similarity to the $S L G$ genes, but are genetically unlinked to the $S$-locus, are designated $S$-locus-related $(S L R)$ genes. Three members of this family, denoted SLR1, SLR2, and SLR3, have been shown to be expressed (Lalonde et al. 1989; Boyes et al. 1991; Cock et al. 1995). Genes SLR1 and SLR2 are linked to each other but unlinked (like $S L R 3$ ) to $S$-locus thus they do not participate directly in the recognition of self and non-self in self-incompatibility. Suzuki et al. (1999) have demonstrated that four of the new $S P$ genes ( $S$-locus protein SP5, SP6, SP8 and SP11) located at $S$-locus of the $S^{9}$ haplotype appear to be expressed

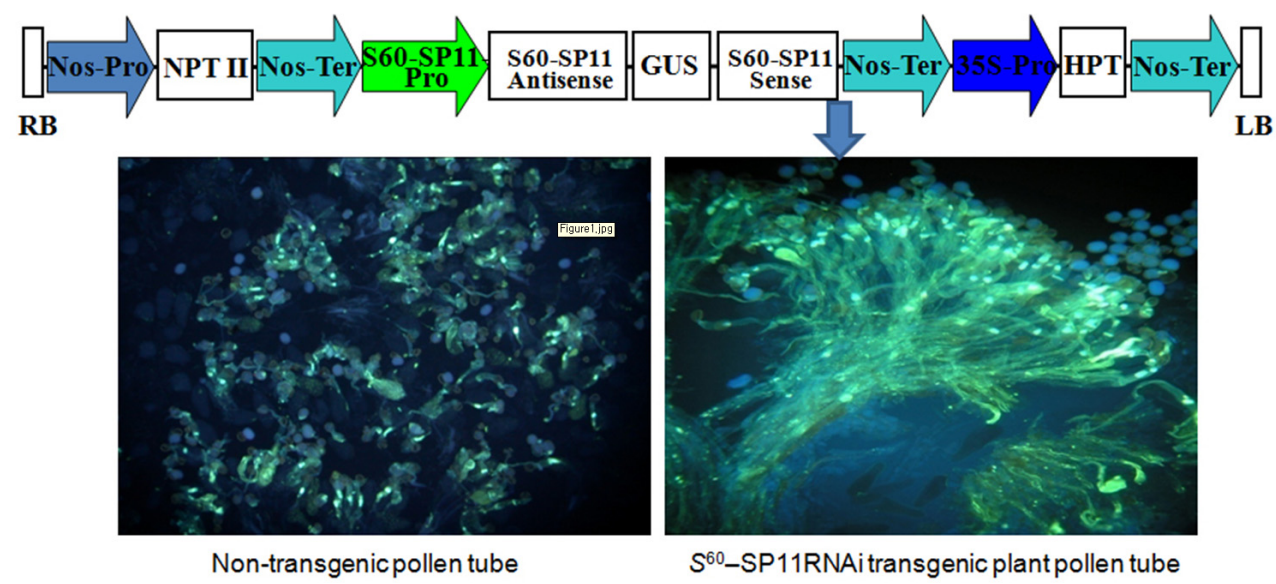

Fig. 1. Schematic representations of the $S^{60}$-SP11RNAi vector construct and consequent pollen-tube behaviors of nontransgenic and RNAi transgenic plants (Jung et al. 2012). 
specifically in reproductive organs. An interesting finding in the study of Suzuki et al. (1999) is that predicted mature protein of SP11 gene is the same protein as male determinant (pollen ligant) of the SI. Schopfer et al. (1999) have published this protein, which they named $S$-locus cysteine-rich protein (SCR), soon after the publication of Suzuki et al. (1999).

\section{Mechanisms involved in the SI reaction}

To date, three polymorphic SI genes have been identified at the $S$-locus of Brassica species. The $S R K$ gene and $S P 11$ gene determine the $S$ specificity of the stigma (Takasaki et al. 2000) and the pollen (Schopfer et al. 1999; Shiba et al. 2001; Shiba et al. 2002; Suzuki et al. 1999; Takayama et al.2000), respectively. The $S L G$ enhances the SI recognition reaction (Takasaki et al. 2000), perhaps by stabilizing $S R K$ (Dixit et al. 2000). The physical interaction between $S P 11$ and $S R K$, and the $S R K$-related signaling cascade following this interaction were the next research targets after identification of both male and female $S$ determinants. Recent biochemical analysis has suggested that $S P 11$ functions as a sole ligand to activate its cognate SRK specifically (Takayama et al. 2001). In the case of self-pollination, SCR protein (pollen ligand) is bound to SRK, resulting in activation of the receptor and initiation of a signal transduction cascade that ultimately leads to pollen inhibition (Kao and McCubbin 2000). It is possible that an $S L G$ has a role in the binding of its cognate $S R K$ with the pollen ligand by forming a complex with the $S$-domain of the SRK and facilitating the process of the recognition reaction (Takasaki et al. 2000).

In the Brassica stigmatic papillae, SRK has been found to be localized to endosomes and the plasma membrane where it is positioned to perceive and bind to the SCR/SP11 protein present in the pollen coat of the self-incompatible pollen (Kachroo et al. 2001; Takayama et al. 2001; Ivanov and Gaude 2009). Interestingly, in the absence of the $S C R / S P 11$ ligand, SRK forms ligand independent dimers (Giranton et al. 2000; Shimosato et al. 2007). The extracellular region contains hypervariable subdomains for ligand-specificity as well and presents a high affinity binding site at the plasma membrane for haplotype-specific SCR/SP11 ligand binding (Kemp and Doughty 2007;
Shimosato et al. 2007; Boggs et al. 2009). Binding of the $\mathrm{SCR} / \mathrm{SP} 11$ ligand results in the phosphorylation and activation of the SRK kinase domain, which in turn leads to further signaling within the stigmatic papilla to produce the pollen rejection response (Kachroo et al. 2001; Takayama et al. 2001; Shimosato et al. 2007). Shimosato et al. (2007) showed that both the $S$-domain and membrane-anchoring domain were necessary for allele-specific interaction by using crosslinking and immunological methods. In contrast, Kachroo et al. (2001) showed that only the $S$-domain of SRK could interact with SP11 in the allele-specific manner by using an immunoprecipitation method. Little is understood about the molecular mechanisms in the SRK-mediated signal transduction pathway. In the future, after determination of the tertiary structure of SRK, this inconsistency is likely to be resolved.

In order to clarify the $S R K$ signaling cascade, several $S R K$-interacting molecules were identified and characterized (Gu et al. 1998; Stone et al. 1999, 2003; Cabrillac et al. 2001; Vanoosthuyse et al. 2003; Murase et al. 2004; Kakita et al. 2007b) Receptor kinase activation typically results in downstream signaling proteins interacting with the activated kinase domain, and consistent with this, several proteins have been found to interact with the SRK kinase domain (Bower et al. 1996; Gu et al. 1998; Vanoosthuyse et al. 2003; Kakita et al. 2007a, b). Two Brassica thioredoxin $h$ proteins, THL1 and THL2, were isolated first (Bower et al. 1996). The thioredoxin $h$ proteins were found to negatively regulate SRK as well as the self-incompatibility response and were proposed to maintain SRK in an inactive state in unpollinated stigmas (Cabrillac et al. 2001; Haffani et al. 2004). Interestingly, THL1 was found to partially co-localize with SRK in the endosomes, but could not be detected at the plasma membrane (Ivanov and Gaude 2009); thus, whether thioredoxin $h$ inhibition of SRK occurs at the plasma membrane is not clear. Nevertheless, this inhibition is proposed to be related with SCR/SP11 ligand binding. A recessive mod mutation which causes a breakdown in Brassica self-incompatibility led to the discovery of the $M$-Locus Protein Kinase (MLPK) encoded by the $\bmod$ locus (Murase et al. 2004). MLPK was found to have serine/threonine activity, and membrane localization of MLPK is required for the self-incompatibility response 
(Murase et al. 2004; Kakita et al. 2007a). MLPK is predicted to interact with SRK at the plasma membrane, and this interaction was demonstrated in BY-2 cells as well as in phosphorylation related studies (Kakita et al. 2007a, b). Thus, MLPK and SRK may form a complex to activate downstream signaling proteins to set the self-incompatibility cellular cascade in motion.

An example of a downstream player is another Brassica interacting protein, $\mathrm{ARC1}$, an E3 ubiquitin ligase also required for the self-incompatibility response (Gu et al. 1998; Stone et al. 1999). The ARC1 protein contains a novel N-terminal domain (UND), followed by a U-box domain and an ARM repeat domain (Samuel et al. 2006). The binding of ARC1 to the phosphorylated SRK kinase domain in vitro is mediated by the ARM repeat domain $(\mathrm{Gu}$ et al. 1998), but interestingly, ARC1 serves as a much better substrate for in vitro phosphorylation by MLPK, supporting the idea of an SRK-MLPK complex activating ARC1 (Samuel et al. 2008a). Because ARC1 is proposed to target a substrate for degradation in the self-incompatibility response, it is reasonable to speculate that $\mathrm{ARC} 1$ functions as an inhibitor of compatibility factors in pollination events as a pollen rejection mechanism (Stone et al. 2003). Not as much is known about the cellular events occurring in a stigmatic papilla during a compatible pollen interaction. Whether activation of this ARC1 E3 ubiquitin degradation pathway is directly responsible for the rejection of selfincompatible pollen has yet to be confirmed, but recently, a new compatibility factor, Exo70A1, which may be the substrate for ARC1's ubiquitin-mediated degradation pathway in this self-incompatibility response, was identified in both Brassica and Arabidopsis (Samuel et al. 2009). A schematic model of the current understanding of Brassica SI reaction is shown in Fig. 2.

\section{Dominance relationships between $S$ alleles}

The majority of the members of the Brassicaceae plant genus Brassica possess a strong sporophytic SI system. An important characteristic of Brassica SI is the dominance relationships between $S$-alleles, which are a consequence of the sporophytic behavior of $S$ genes (Thompson and Taylor 1966, Hatakeyama et al. 1998, Bateman 1952, 1954, 1955). Thus, the SI phenotype of pollen as well as stigma is determined by relationships between the two $S$-haplotypes carried by its parent (Bateman 1955). In other words, a codominant or a dominant/recessive relationship

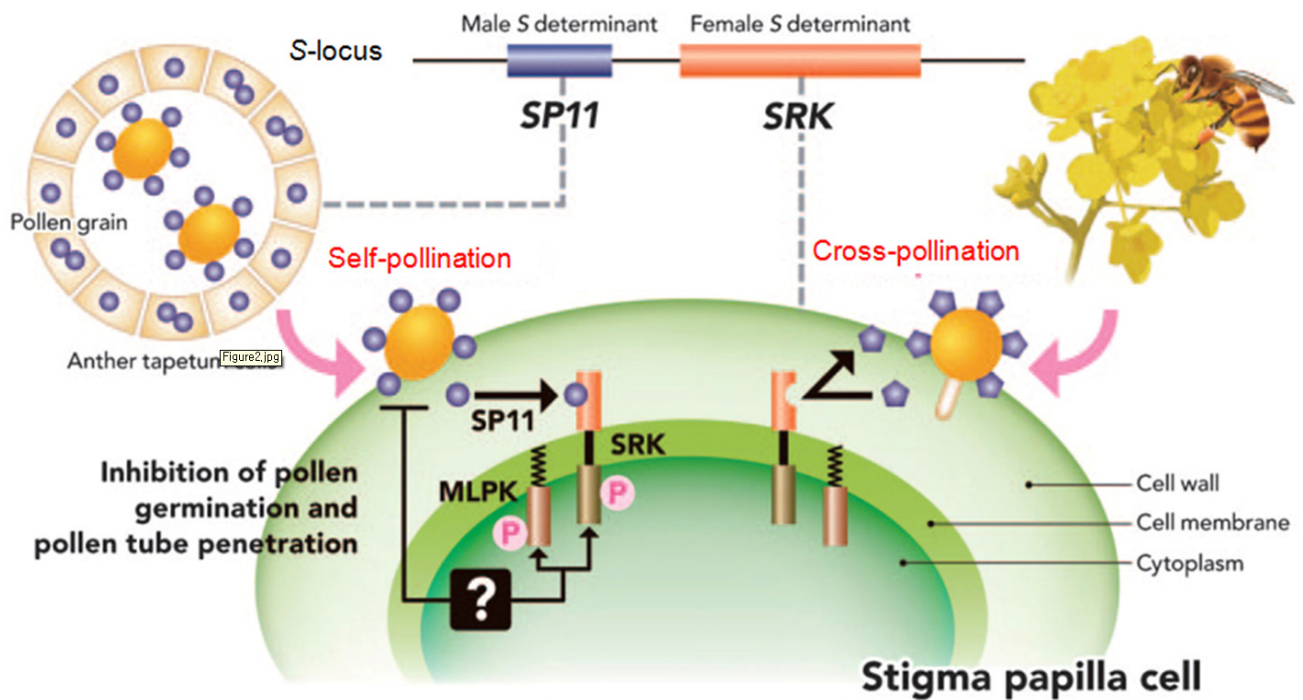

Fig. 2. Schematic model for self-pollen recognition in Brassica species. Male and female S determinant genes, SP11 and $S R K$, are located at the $S$-locus. SP11 is predominantly expressed in the tapetum cells of anther locules, and accumulates on the pollen surface during pollen maturation. During self-pollination, SP11 molecules penetrate into the papilla cell wall, and interact with $S R K$ in an $S$-allele-specific manner. Phosphorylated $S R K$ interacts with MLPK. After the subsequent signal transduction, which has not yet been determined, rejection of the self-pollen occurs (Watanabe et al. 2012). 
between the two $S$-haplotypes influences the ultimate SI phenotype of both pollen and stigma (Thompson and Taylor 1966). The following observations have been made about dominance relationships among $S$-haplotypes: (1) codominance is more frequent than dominance/recessiveness; (2) dominance/ recessiveness in the pollen is observed more frequently than that in the stigma; (3) dominance relationships among stigmas are different from those among pollen; and (4) dominance relationships are non-linear, and are more frequent in the stigma than in the pollen (Thompson and Taylor 1966; Ockendon 1975; Visser et al. 1982; Hatakeyama et al. 1998). Discovery of the molecular mechanisms of dominance relationships has been based on these genetic features.

The different mechanisms operating in the male and female side in the dominance relationships of SI are consistent with the four genetic characteristics described above. Dominance relationships of SI at the female side appear to be post-transcriptionally regulated by $S R K$, unlike transcriptional suppression of SP11 (Hatakeyama et al. 2001). They investigated whether the stigmatic $S$-determinant of SRK was involved in determining the dominance relationships of stigma using five $S$-homozygotes carrying an SRK28 transgene. They showed that the dominance relationship between the SRK28 transgene and each of the endogenous $S$-haplotypes was identical to that between the $S^{28}$-haplotype and the respective endogenous $S$-haplotype. Moreover, in the $S^{43} S^{43}$-homozygote carrying the $S R K 28$ transgene, in which the $S^{43}$ phenotype in the stigma was masked by the presence of $S R K 28$, the transcript level of $S R K 28$ was found to be much lower than that of SRK43. These results suggest that the dominant/

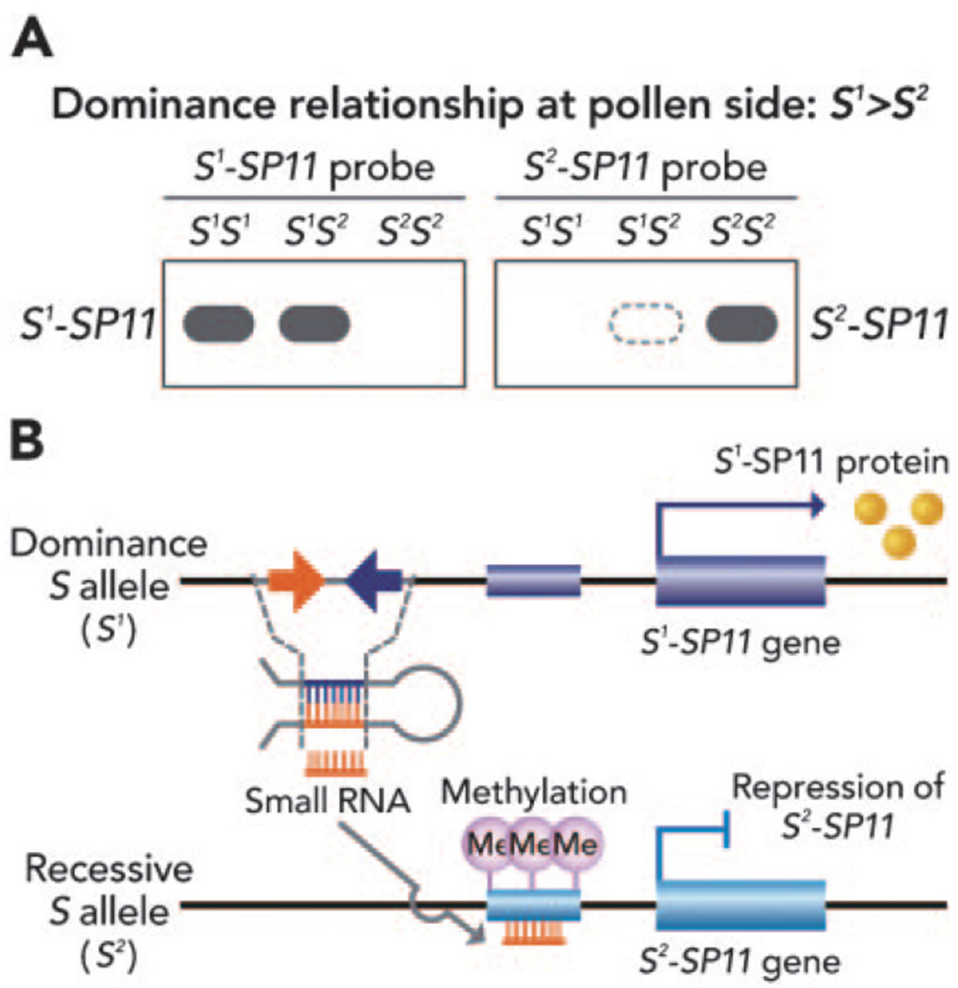

Fig. 3. Schematic model for molecular mechanisms of dominance relationships at the pollen side. (A) In the case where $S^{l}$ is dominant over $S^{2}$, dominant transcripts of $S P 11, S^{l}-S P 11$, are specifically expressed in the $S^{l} S^{2}$ heterozygote. However, $S^{2}-S P 11$ transcripts are not detected in the $S^{l} S^{2}$ heterozygote on RNA gel blot analysis. The results demonstrate that the dominance relationship at the pollen side is regulated at the transcriptional level. (B) In the dominant $S$-allele, small RNA, termed Smi (SP11 methylation inducer), is specifically produced, and its nucleotide sequence is highly similar to the promoter region of the recessive SPI1 gene. This small RNA induces the methylation of recessive $S P 11$, and represses the recessive $S P 11$ at the transcriptional level (Watanabe et al. 2012). 
recessive relationships between $S$-haplotypes in the stigma are determined by SRK itself, but not as a result of its relative transcription level.

Regarding dominance relationships in pollen, the pollen determinant SP11 from pollen-recessive $S$-haplotypes has not been identified, and how the relationships are determined is not known. The dominance relationships of SI are regulated by transcription of SP11 in Brassica pollen. In sporophytic tapetum cells of anthers of $\mathrm{S}$ heterozygous plants, $S P 11$ derived from the dominant allele is normally expressed, whereas expression of the recessive SP11 is significantly suppressed (Fig. 3A) (Shiba et al. 2002; Kakizaki et al. 2003) Interestingly, linear dominance relationships $\left(S^{9}>S^{44}>S^{60}>S^{40}>S^{29}\right)$ are also observed in B. rapa (Hatakyama et al. 1998; Kakizaki et al. 2003). In this case, dominance/recessiveness of $S^{44}, S^{60}, S^{40}$ alleles could be altered, indicating involvement of epigenetic regulation (Kakizaki et al. 2003). From observation of the methylation level of the promoter region of $S P 11$ in several $S$ heterozygotes, it was shown that the recessive $S P 11$ is specifically methylated in $S$ heterozygotes (Shiba et al. 2006). Recently, it was further demonstrated that the small RNA produced from the dominant allele could activate methylation of the recessive allele. In transgenic experiments, $S^{60}$ (class II) transformants with a class-Iderived small RNA region $\left(S^{9}\right)$ showed $\mathrm{SC}$, and their promoter regions were highly methylated, as in the $S^{9} S^{60}$ heterozygote, indicating that the small RNA from the dominant allele functions in trans to induce transcriptional silencing of the recessive allele (Fig. 3B; Tarutani et al. 2010) However, it has been suggested that pollen-recessive $S$-haplotypes have a set of $S L G$ and $S R K$ called class II, whereas pollen-dominant $S$-haplotypes have a different set called class I (Nasrallah and Nasrallah 1993).

Furthermore, based on the sequence diversity of the SI genes, $S$ haplotypes are classified into class I and class II; the amino acid sequence similarity of SLG and SRK is about $65 \%$ between classes and $80-90 \%$ within classes (Watanabe et al. 2001). On the other hand, amino acid sequence identities among class II SP11s are 62.3 to $94.6 \%$, rather higher compared with those of class I SP11s which ranges from 19.5 to $76.1 \%$ (Shiba et al. 2002). Interestingly, class-I $S$ haplotypes are dominant over class-II ones in the dominance relationships on the pollen side (Hatakeyama et al. 1998, Nasrallah and Nasrallah 1993, Thompson and Taylor 1966). To date, class II $S L G$ s have been found only in pollen-recessive $S$-haplotypes, which include $S^{29}-, S^{40}$-, $S^{44}$-, and $S^{60}$-haplotypes of $B$. rapa (syn. campestris) (Hatakeyama et al. 1998; Takasaki et al. 2000) and S2-, S5-, and S15-haplotypes of B. oleracea (Chen and Nasrallah 1990; Scutt and Croy 1992; Cabrillac et al. 1999). The pairwise sequence identity among class II SLGs is in excess of $86 \%$, whereas that between class I and class II SLGs is only $\sim 60$ to $70 \%$. The extracellular domains of pollen-dominant and pollen-recessive SRKs also can be placed into these two classes in a similar manner. These analytical results on stigmatic $S$-locus proteins suggest that class II $S$-haplotypes have an origin quite different from that of class I $S$-haplotypes (Uyenoyama 1995; Kusaba et al. 1997; Schierup et al. 2001).

\section{Future outlook}

SI is one of the most interesting phenomena in sexual reproduction and the molecular genetics processes in sexual plant reproduction research have now been extensively dissected in Brassicaceae plants. In recent years, significant progress has been made in strengthening our understanding of the molecular and cellular steps behind the self-incompatibility response in the Brassicaceae. Such accumulation of biological and molecular genetic knowledge will also contribute to the understanding of interesting biological features, including cell-cell communication, ligand-receptor interaction, signal transduction, phosphorylation cascade, molecular evolution, allelic polymorphism and epigenetic regulation by small RNAs in the SI recognition reaction. However, there are areas that still require further dissection, and current research is aimed at more fully understanding the specific signaling events that take place in the stigmatic papillae following pollination. For example, efforts have focused on identifying residues within the SRK extracellular domain that are essential for its activation by the SCR/SP11 ligand. It appears that a surprisingly small number of residues are required, and that the three-dimensional conformation of these regions is a determining factor (Boggs et al. 2009). Outstanding questions also encompass the regulatory role of $M L P K$, in relation to $S R K$, on downstream signaling 
steps including $A R C l$ and perhaps other unknown signaling proteins or events. To elucidate a complete overview of the peptide signaling, further analysis of protein-protein interaction by the use of yeast two-hybrid system, protein cross-linking, etc. is required (Hattori et al. 2009; Shinya et al. 2010), in addition to the genetic analysis described above. Furthermore, when the tertiary structure of $S R K$ has been carried out and established, the precise SP11-SRK allelic-specific interaction will provide new insight into SP11-induced SRK activation. In summary, the dissection of cellular events activated in the self-incompatibility response and understanding molecular mechanism of the SI recognition reaction in the Brassicaceae has started to uncover which will also be important in establishing $F_{1}$ hybrid seed production in the future.

\section{ACKNOWLEDGMENT}

This work was supported by a grant from the NextGeneration BioGreen 21 Program (Plant Molecular Breeding Center No. PJ009085022013), Rural Development Administration, Republic of Korea.

\section{REFERENCES}

Bateman AJ. 1952. Self-incompatibility systems in angiosperms. I. Theory. Heredity 6: 285-310.

Bateman AJ. 1954. Self-incompatibility systems in angiosperms. II. Iberis amara. Heredity 8: 305-332.

Bateman AJ. 1955. Self-incompatibility systems in angiosperms. III. Cruciferae. Heredity 9: 53-68

Boggs NA, Dwyer KG, Nasrallah ME, Nasrallah JB. 2009. In vivo detection of residues required for ligand selective activation of the $S$-locus Receptor in Arabidopsis. Curr. Biol. 19: 786-791.

Bower MS, Matias DD, Fernandes-Carvalho E, Mazzurco M, $\mathrm{Gu}$ T, Rothstein SJ, Goring DR. 1996. Two members of the thioredoxin-h family interact with the kinase domain of a Brassica S-locus receptor kinase. Plant Cell. 8: 1641-1650.

Boyes DC, Chen CH, Tatikanjana T, Esch JJ, Nasrallah JB. 1991. Isolation of a second $S$-locus-related cDNA from Brassica oleracea: genetic relationships between the
$S$-locus and two related loci. Genetics. 127: 221-228.

Boyes DC, Nasrallah JB. 1995. An anther-specific gene encoded by an $S$-locus haplotype of Brassica produces complementary and differentially regulated transcripts. Plant Cell. 7: 1283-1294.

Boyes DC, Nasrallah ME, Vrebalov J, Nasrallah JB. 1997. The self-incompatibility (S) haplotypes of Brassica contain highly divergent and rearranged sequences of ancient origin. Plant Cell. 9: 237-247.

Brace J, Rydes CD, Ockedon DJ. 1994. Identification of $S$-alleles in Brassica oleracea. Euphytica. 80: 229-234.

Cabrillac D, Cock JM, Dumas C, Gaude T. 2001. The $S$-locus receptor kinase is inhibited by thioredoxins and activated by pollen coat proteins. Nature. 410: 220-223.

Cabrillac D, Delorme V, Garin J, Ruffio-Châble V, Giranton JL, Dumas C, Gaude T, Cock JM. 1999. The S15 selfincompatibility haplotype in Brassica oleracea includes three $S$ gene family members expressed in stigmas. Plant Cell. 11: 971-986.

Casselman AL, Vrebalov J, Conner JA, Singal A, Giovanni J, Nasrallah ME, Nasrallah JB. 2000. Determining the physical limits of the Brassica $S$-locus by recombinational analysis. Plant Cell. 12: 23-33.

Chen CH, Nasrallah JB. 1990. A new class of $S$ sequences defined by a pollen recessive self-incompatibility allele of Brassica oleracea. Mol. Gen. Genet. 222: 241-248.

Cock JM, Stanchev B, Delorme V, Croy RRD, Dumas CH. 1995. SLR3: a modified receptor kinase gene that has been adapted to encode a putative secreted glycoprotein similar to the S-locus glycoprotein. Mol. Gen. Genet. 248: 151-161.

De Nettancourt D. 1977. Incompatibility in angiosperms. Berlin: Springer-Verlag. pp. 230.

De Nettancourt D. 2001. Incompatibility and incongruity in wild and cultivated plants, $2^{\text {nd }}$ ed., Springer, Berlin, Heidelberg, New York. pp.1-322.

Dixit BL, Balendiran GK, Watowich SJ, Srivastava SK, Ramana KV, Petrash JM, Bhatnagar A. 2000. Kinetic and structural characterization of the glutathione binding site of aldose reductase. J. Biol. Chem. 275: 21587-21595.

Doughty J, Dixon S, Hiscock SJ, Willis AC, Parkin IAP, Dickinson HG. 1998. PCPA1, a difensin-like Brassica pollen coat protein that binds the $S$-locus glycoprotein, is the product of gametophytic gene expression. Plant Cell. 10: 1333-1347.

Doughty J, Hedderson F, McCubbin A, Dickinson HG. 1993. Interaction between acoating-borne peptide of the Brassica 
pollen grain and stigmatic S (self-incompatibility)-locusspecific glycoproteins. Proc. Natl. Acad. Sci. USA. 90: 467-471.

Entani T, Iwano M, Shiba H, Che FS, Isogai A, et al. 2003. Comparative analysis of the self-incompatibility (S-) locus region of Prunus mume: identification of a pollenexpressed F-box gene with allelic diversity. Genes Cells 8: 203-213.

Fisher RA. 1958. The Genetical Theory of Natural Selection, Ed. 2. Dover, New York.

Fukai E, Fujimoto R, Nishio T. 2003. Genomic organization of the $S$ core region and the $S$ flanking regions of a class-II S haplotype in Brassica rapa. Mol. Genet. Genomics. 269: 361-369.

Gaude T, Rougier M, Heizmann P, Ockendon DJ, Dumas C. 1995. Expression level of the $S L G$ gene is not correlated with the self-incompatibility phenotype in the class II $S$ haplotypes of Brassica oleracea. Plant Mol. Biol. 27: 1003-1014.

Giranton JL, Dumas C, Cock JM, Gaude T. 2000. The integral membrane $S$-locus receptor kinase of Brassica has serine/ threonine kinase activity in a membranous environment and spontaneously forms oligomers in planta. Proc. Natl. Acad. Sci. USA. 97: 3759-3764.

Goring DR, Glavin TL, Schafer U, Rothstein SJ. 1993. An $S$ receptor kinase gene in self-compatible Brassica napus has a 1-bp deletion. The Plant Cell 5: 531-53.

Goring DR, Rothstein SJ. 1992. The $S$-locus receptor kinase gene in self-incompatible Brassica napus line encodes a functional serine/threonine kinase. Plant Cell 4: 1273-1281.

Gu T, Mazzurco M, Sulaman W, Matias DD, Goring DR. 1998. Binding of an arm repeat protein to the kinase domain of the $S$-locus receptor kinase. Proc. Natl. Acad. Sci. USA 95: 382-387.

Haffani YZ, Gaude T, Cock JM, Goring DR. 2004. Antisense suppression of thioredoxin h mRNA in Brassica napus cv. Westar pistils causes a low level constitutive pollen rejection response. Plant Mol. Biol. 55: 619-630.

Hatakeyama K, Watanabe M, Takasaki T, Ojima K, Hinata K. 1998. Dominance relationships between $S$-alleles in self-incompatible Brassica campestris L. Heredity. 79: 241-247.

Hattori Y, Nagai K, Furukawa S, Song XJ, Kawano R, Sakakibara H, Wu J, Matsumoto T, Yoshimura A, Kitano H, Matsuoka M, Mori H, Ashikari M. 2009. The ethylene response factors SNORKEL1 and SNORKEL2 allow rice to adapt to deep water. Nature. 460: 1026-1030.
Heslop-Harrison J. 1975. Incompatibility and the pollen-stigma interaction. Annu. Rev. Plant Physiol. 26: 403-425.

Hiscock SJ, Doughty J, Willis AC, Dickinson HG. 1995. A $7-\mathrm{kDa}$ pollen coatingborne peptide from Brassica napus ineracts with $S$-locus glycoprotein and $S$-locus related glycoprotein. Planta 196: 367-374.

Ivanov R, Gaude T. 2009. Endocytosis and endosomal regulation of the $S$-receptor kinase during the self-incompatibility response in Brassica oleracea. Plant Cell 21: 2107-2117.

Jung HJ, Jung HJ, Ahmed NU, Park JI, Kang KK, Hur Y, Lim YP, Nou IS. 2012. Development of Self-compatible $B$. rapa by RNAi-mediated $S$-locus Gene Silencing. Plos one. 7(11): e49497.

Kachroo A, Schopfer CR, Nasrallah ME, Nasrallah JB. 2001. Allele-specific receptor-ligand interactions in Brassica self-incompatibility. Science. 293: 1824-1826.

Kakita M, Murase K, Iwano M, Matsumoto T, Watanabe M, Shiba H, Isogai A, Takayama S. 2007a. Two distinct forms of $M$-locus protein kinase localize to the plasma membrane and interact directly with $S$-locus receptor kinase to transduce self-incompatibility signaling in Brassica rapa. Plant Cell. 19: 3961-3973.

Kakita M, Shimosato H, Murase K, Isogai A, Takayama S. 2007b. Direct interaction between the $S$-locus receptor kinase and $M$-locus protein kinase involved in Brassica self-incompatibility signaling. Plant Biotech. 24: 185-190.

Kakizaki T, Takada Y, Ito A, Suzuki G, Shiba H, Takayama S, Isogai A, Watanabe M. 2003. Linear dominance relationship among four class-II $S$-haplotypes in pollen side determined by the expression of SP11 in Brassica self-incompatibility. Plant Cell Physiol. 44: 70-75.

Kao TH, McCubbin AG. 2000. A social stigma. Nature 403: 840-841.

Kemp B, Doughty J. 2007. S cysteine-rich (SCR) binding domain analysis of the Brassica self-incompatibility $S$-locus receptor kinase. New Phytol. 175: 619-629.

Kusaba M, Nishio T, Satta Y, Hinata K, Ockedon D. 1997. Striking sequence similarity in inter- and intra-specific comparisons of class I SLG alleles from Brassica oleracea and Brassica campestris: Implications for the evolution and recognition mechanism. Proc. Natl. Acad. Sci. USA. 94: 7673-7678.

Lalonde BA, Nasrallah ME, Dwyer KG, Chen CH, Barlow B, Nasrallah JB. 1989. A highly conserved Brassica gene with homology to the $S$-locus-specific glycoprotein structural gene. Plant Cell 1: 249-258.

Letham DLD, Nasrallah JB. 1998. A ClpP homolog linked to 
the Brassica self-incompatibility (S) locus. Sex. Plant. Reprod. 11: 117-119.

Murase K, Shiba H, Iwano M, Che FS, Watanabe M, Isogai A, Takayama S. 2004. A membrane-anchored protein kinase involved in Brassica self-incompatibility signaling. Science 303: 1516-1519.

Nasrallah JB, Kao TH, Goldberg ML, Nasrallah ME. 1985. A cDNA clone encoding an $S$-locus specific glycoprotein from Brassica oleracea. Nature 318: 263-267.

Nasrallah JB, Nasrallah ME. 1993. Pollen-stigma signaling in the sporophytic self-incompatibility response. Plant Cell 5: 1325-1335.

Nasrallah JB, Nishio T, Nasrallah ME. 1991. The selfincompatibility genes of Brassica: Expresion and use in genetic ablation of floral tissues. Annu. Rev. Plant Physiol. Plant Mol. Biol. 42: 393-422.

Nasrallah JB, Rundle SJ, Nasrallah ME. 1994. Genetic evidence for the requirement of Brassica oleracea $S$-locus receptor kinase in the self-incompatibility response. Plant J. 5: 373-384.

Nasrallah ME, Kandasamy MK, Nasrallah JB. 1992. A genetically defined trans-acting locus regulates $S$-locus function in Brassica. Plant J. 2: 497-506.

Nasrallah ME, Liu P, Nasrallah JB. 2002. Generation of self-incompatible Arabidopsis thaliana by transfer of two $S$-locus genes from A. lyrata. Science. 297: 247-249.

Nasrallah ME, Liu P, Sherman-Broyles S, Broggs NA, Nasrallah JB. 2004. Natural variation in expression of self-incompatibility in Arabidopsis thaliana: implications for the evolution of selfing. Proc. Natl. Acad. Sci. USA. 101: 16070-16074.

Nou I, Watanabe M, Isogai A, Hinata K. 1993. Comparison of $S$-alleles and $S$-glycoproteins between two wild populations of Brassica campestris in Turkey and Japan. Sex. Plant Reprod. 6: 79-86.

Ockendon DJ. 1975. Dominance relationships between $S$-alleles in the stigma of Brussels sprouts (Brassica oleracea var. gemmifera). Euphytica. 24: 165-172.

Pastuglia M, Roby D, Dumas C, Cock JM. 1997a. Rapid induction by wounding and bacterial infection of an $S$-gene family receptor-like kinase gene in Brassica oleracea.Plant Cell 9: 49-60.

Pastuglia M, Ruffio-Chable V, Delorme V, Gaude T, Dumas C, Cock JM. 1997b. A functional $S$-locus anther gene is not required for the self-incompatibility response in Brassica oleracea. Plant Cell. 9: 2065-2076.

Sampson DR. 1957. The genetics of self-incompatibility in the radish. J. Heredity 48: 26-29.

Samuel M, Salt J, Shiu S, Goring D. 2006. Multifunctional arm repeat domains in plants. Int. Rev. Cytol. 253: 1-26.

Samuel MA, Chong YT, Haasen KE, Aldea-Brydges MG, Stone SL, Goring DR. 2009. Cellular pathways regulating responses to compatible and self-incompatible pollen in Brassica and Arabidopsis stigmas intersect at Exo70A1, a putative component of the exocyst complex. Plant Cell 21: 2655-2671.

Samuel MA, Mudgil Y, Salt JN, Delmas F, Ramachandran S, Chilelli A, Goring DR. 2008. Interactions between the $S$-domain receptor kinases and AtPUB-ARM E3 ubiquitin ligases suggest a conserved signaling pathway in Arabidopsis. Plant Physiol. 147: 2084-2095.

Schierup MH, Mable BK, Awadalla P, Charlesworth D. 2001. Identification and characterization of a polymorphic receptor kinase gene linked to the self-incompatibility locus of Arabidopsis lyrata. Genetics 158: 387-399.

Schopfer CR, Nasrallah ME, Nasrallah JB. 1999. The male determinant of self-incompatibility in Brassica. Science. 286: 1697-1700.

Scutt CP, Croy RRD. 1992. An S5 self-incompatibility allele-specific cDNA sequence from Brassica oleracea shows high homology to the SLR2 gene. Mol. Gen. Genet. 232: 240-246.

Shiba H, Hinata K, Suzuki A, Isogai A. 1995. Breakdown of self-incompaibility in Brassica by the antisense RNA of the SLG. Proc. Jpn. Acad. 71: 81-83.

Shiba H, Iwano M, Entani T, Ishimoto K, Shimosato H, Che FS, Satta Y, Ito A, Takada Y, Watanabe M, Isogai A, Takayama S. 2002. The dominance of alleles controlling self-incompatibility in Brassica pollen is regulated at the RNA level. Plant Cell 14: 491-504.

Shiba H, Kakizaki T, Iwano M, Tarutani Y, Watanabe M, Isogai A, Takayama S. 2006. Dominance relationships between self-incompatibility alleles controlled by DNA methylation. Nat. Genet. 38: 297-299.

Shiba H, Kenmochi M, Sugihara M, Iwano M, Kawasaki S. 2003. Genomic organization of the $S$-locus region of Brassica. Biosci. Biotechnol. Biochem. 67: 622-626.

Shiba H, Takayama S, Iwano M, Shimosato H, Funato M, Nakagawa T, Che FS, Suzuki G, Watanabe M, Hinata K, Isogai A. 2001. A pollen coat protein, SP11/SCR, determines the pollen $S$-specificity in the self-incompatibility of Brassica species. Plant Physiol. 125: 2095-2103.

Shimosato H, Yokota N, Shiba H, Iwano M, Entani T, Che FS, Watanabe M, Isogai A, Takayama S. 2007. 
Characterization of the SP11/SCR high-affinity binding site involved in self/nonself recognition in Brassica self-incompatibility. Plant Cell 19: 107-117.

Shinya T, Osada T, Desaki Y, Hatamoto M, Yamanaka Y, Hirano H, Takai R, Che FS, Kaku H, Shibuya N. 2010. Characterization of receptor proteins using affinity cross-linking with biotinylated ligands. Plant Cell Physiol. 51: $262-270$

Stanchev BS, Doughty J, Scutt CP, Dickinson HG, Croy RRD. 1996. Cloning of $P C P 1$, a member of a family of pollen coat protein (PCP) genes from Brassica oleracea encoding novel cysteine-rich proteins involved in pollen-stigma interactions. Plant J. 10: 303-313.

Stein JC, Howlett B, Boyes DC, Nasrallah ME, Nasrallah JB. 1991. Molecular cloning of putative receptor protein kinase gene encoded at the self-incompatibility locus of Brassica oleracea. Proc. Natl. Acad. Sci. USA. 88: 8816-8820.

Stephenson AG, Doughty J, Dixon S, Elleman C, Hiscock S, Dickinson HG. 1997. The male determinant of selfincompatibility in Brassica oleracea is located in the pollen coating. The Plant Journal 12: 1351-1359.

Stone SL, Anderson EM, Mullen RT, Goring DR. 2003. $A R C 1$ is an E3 ubiquitin ligase and promotes the ubiquitination of proteins during the rejection of selfincompatible Brassica pollen. Plant Cell 15: 885-898.

Stone SL, Arnold M, Goring DR. 1999. A breakdown of Brassica self-incompatibility in $A R C 1$ antisense transgenic plants. Science 286: 1729-1731.

Suzuki G, Kai N, Hirose T, Fukui K, Nishio T, Takayama S, Isogai A, Watanabe M, Hinata K. 1999. Genomic organization of the $S$-locus: identification and characterization of genes in SLG/SRK region of $S 9$ haplotype of Brassica campestris (syn. rapa). Genetics 153: 391-400.

Takasaki T, Hatakeyama K, Suzuki G, Watanabe M, Isogai A, Hinata K. 2000. The $S$ receptor kinase determines self-incompatibility in Brassica stigma. Nature 403: 913-916.

Takayama S, Isogai A. 2005. Self-incompatibility in plants. Annu. Rev. Plant Biol. 56: 467-489.

Takayama S, Shiba H, Iwano M, Asano K, Hara M, Che FS, Watanabe M, Hinata K, Isogai A. 2000a. Isolation and characterization of pollen coat proteins of Brassica campestris that interact with $S$-locus-related glycoprotein 1 involved in pollen-stigma adhesion. Proc. Natl. Acad. Sci. USA. 97: 3765-3770.

Takayama S, Shiba H, Iwano M, Shimosato H, Che FS, Kai
N, Watanabe M, Suzuki G, Hinata K, Isogai A. 2000b. The pollen determinant of self-incompatibility in Brassica campestris. Proc. Natl. Acad. Sci. USA. 97: 1920-1925.

Takayama S, Shimosato H, Shiba H, Funato M, Che FS, Watanabe M, Iwano M, Isogai A. 2001. Direct ligandreceptor complex interaction controls Brassica selfincompatibility. Nature 413: 534-538.

Tarutani Y, Shiba H, Iwano M, Kakizaki T, Suzuki G, Watanabe M, Isogai A, Takayama S. 2010. Trans-acting small RNA determines dominance relationships in Brassica self-incompatibility. Nature 466: 983-986.

Thomson KF, Taylor JP. 1966. Non-linear dominance relationships between $S$-alleles. Heredity 21: 345-362.

Toriyama K, Hanaoka K, Okada T, Watanabe M. 1998. Molecular cloning of a cDNA encoding a pollen extracellular protein as a potential source of a pollen allergen in Brassica rapa. FEBS Lett. 424: 234-238.

Toriyama K, Stein JC, Nasrallah ME, Nasrallah JB. 1991. Transformation of Brassica oleracea with an $S$-locus gene from $B$. campestris changes the self-incompatibility phenotype. Theor. Appl. Genet. 81: 769-776.

Tsuchimatsu T, Suwabe K, Shimizu-Inatsugi R, Isokawa S, Pavlidis P, Städler T, Suzuki G, Takayama S, Watanabe M, Shimizu KK. 2010. Evolution of self-compatibility in Arabidopsis by a mutation in the male specificity gene. Nature 464: 1342-1346.

Uyenoyama MK. 1995. A generalized least-squares estimate for the origin of sporophytic self-incompatibility. Genetics 139: 975-992.

Vanoosthuyse V, Tichtinsky G, Dumas C, Gaude T, Cock JM. 2003. Interaction of calmodulin, a sorting nexin and kinase-associated protein phosphatase with the Brassica oleracea S-locus receptor kinase. Plant Physiol. 133: 919-929.

Visser DL, van Hal JG, Verhoeven W. 1982. Classification of $S$-alleles by their activity in $S$-heterozygotes of Brussels sprouts (Brassica oleracea var. gemmifera (DC.) Schultz). Euphytica 31: 603-611.

Watanabe M, Hinata K. 1999. Self-incompatibility. In Biology of Brassica Coenospecies (ed. Gomez-Campo, C.). Elsevier, Amsterdam. pp.149-183.

Watanabe M, Ito A, Takada Y, Ninomiya C, Kakizaki T, Takahata Y, Hatakeyama K, Hinata K, Suzuki G, Takasaki T, Satta Y, Shiba H, Takayama S, Isogai A. 2000. Highly divergent sequence of the pollen selfincompatibility (S) gene in class-I Shaplotypes of Brassica campestris (syn. rapa) L. FEBS Lett. 12: 139-144. 
Watanabe M, Suwabe K, Suzuki G. 2012. Molecular genetics, physiology and biology of self-incompatibility in Brassicaceae. Proc. Jpn. Acad., Ser. 88(10): 519-535.

Watanabe M, Suzuki G, Takayama S. 2008. Chapter 7: Milestones identifying self-incompatibility genes in Brassica species: From old stories to new findings. In Self-incompatibility in Flowering Plants-Evolution,
Diversity, and Mechanisms (ed. Franklin-Tong, V.E.), Springer, Berlin, Heidelberg, New York. pp.151-172.

Wright S. 1939. The distribution of self-sterility alleles in populations. Genetics 24: 538-552.

Yu K, Schafer U, Glavin TL, Goring DR, Rothstein S. 1996. Molecular characterization of the $S$-locus in two selfincompatible Brassica napus lines. Plant Cell 8: 2369-2380. 